www.jmscr.igmpublication.org

Impact Factor (SJIF): 6.379

Index Copernicus Value: 71.58

ISSN (e)-2347-176x ISSN (p) 2455-0450

crossref DOI: _https://dx.doi.org/10.18535/jmscr/v6i4.48

Journal Of Medical Science And Clinical Research

IGM Publication

An Official Publication of IGM Publication

\title{
Role of MRI in characterisation of Endometriomas, primarily evaluated by ultrasonography and to compare with clinical, surgical and Histopathological data
}

\author{
Authors \\ Dr Sweta Singh MBBS ${ }^{1}$, Dr Sandip Kumar Ghosh MBBS MD², \\ Dr Sumanta Kumar Mandal, MBBS, MD $^{3}$ \\ ${ }^{1}$ Post Graduate Trainee, Bankura Sammilani Medical College and Hospital \\ ${ }^{2}$ Associate Professor, Bankura Sammilani Medical College and Hospital \\ ${ }^{3}$ Associate Professor, Bankura Sammilani Medical College and Hospital
}

\section{Background}

Endometriomas occurs when the ectopic endometrial tissue implants enlarge and repeatedly haemorrhage in response to hormonal stimulation forming cystic lesion commonly on the ovaries. T2 shading is the classic MR feature of an Endometrioma and is defined as a cystic lesion with hyperintense signal on a $\mathrm{T} 1$ weighted image that demonstrates T2 shortening resulting in relative hypointensity on $\mathrm{T} 2$ weighted image. However T2 shading can be seen in other haemorrhagic adnexal lesions namely haemorrhage cysts. Intra cystic T2 dark spot has high specificity for chronic haemorrhage and is useful to differentiate endometriomas from haemorrhagic cysts.

\section{Objectives}

The present study was conducted in a bid to determine the sensitivity, specificity and accuracy of MRI in identifying endometriomas in USG diagnosed cystic ovarian lesions.

\section{Materials and Methods}

The present study was conducted in the Department of Radiodiagnosis, Bankura Sammilani Medical College, during the period of 1 year. 65 females who attended the USG section of the Department of Radiodiagnosis after being referred from gynaecology and obstetrics Department, Department of General Surgery and few from General Medicine were evaluated using ultrasonography primarily. Out of these, 5 patients were pregnant, 2 had a pacemaker installed and 5 were follow up/ post operative cases. We excluded these patients. Complete data collection and follow up was possible in only 53 patients.

All the patients included in our study underwent a transabdominal/ transvaginal examination on HD7 Philips machine, adnexal pathology was confirmed. Out of these, 38 were purely cystic lesions and these patients were scheduled for MRI after taking an informed consent.

Pelvic MRI was done on a 1.5 TESLA GE Scanner. Scanning was performed after a fasting period of 4-6 hours prior to the examination. Imaging was done in supine position with a 
surface coil placed on the torso to cover the entire imaging area.T1, T2, T1 and T2 fat sat images were obtained in axial, coronal and sagittal planes. Post contrast images were also taken. Gadolinium dimeglumine was used $10 \mathrm{ml}$ as contrast. All cases showing presence of fat on MRI, multiple thick septae, vegetations, honey combing, loculi were excluded. Patients with haemorrhagic cysts were included in the study.

The data was then analysed using SPSS 22.0 and Microsoft word and excel sheets have been used to generate graphs and tables.

\section{Results and Observation}

The 53 patients included in our study showed the following features-

a) Patients with benign ovarian pathology presented with following complaints:

\begin{tabular}{|l|c|c|}
\hline & number & $\%$ \\
\hline Lump abdomen & 15 & 54 \\
\hline Pain abdomen & 13 & 46 \\
\hline Dysmenorrhoea & 7 & 25 \\
\hline Dyspareunia & 2 & 7 \\
\hline Infertility & 2 & 7 \\
\hline asymptomatic & 2 & 7 \\
\hline
\end{tabular}

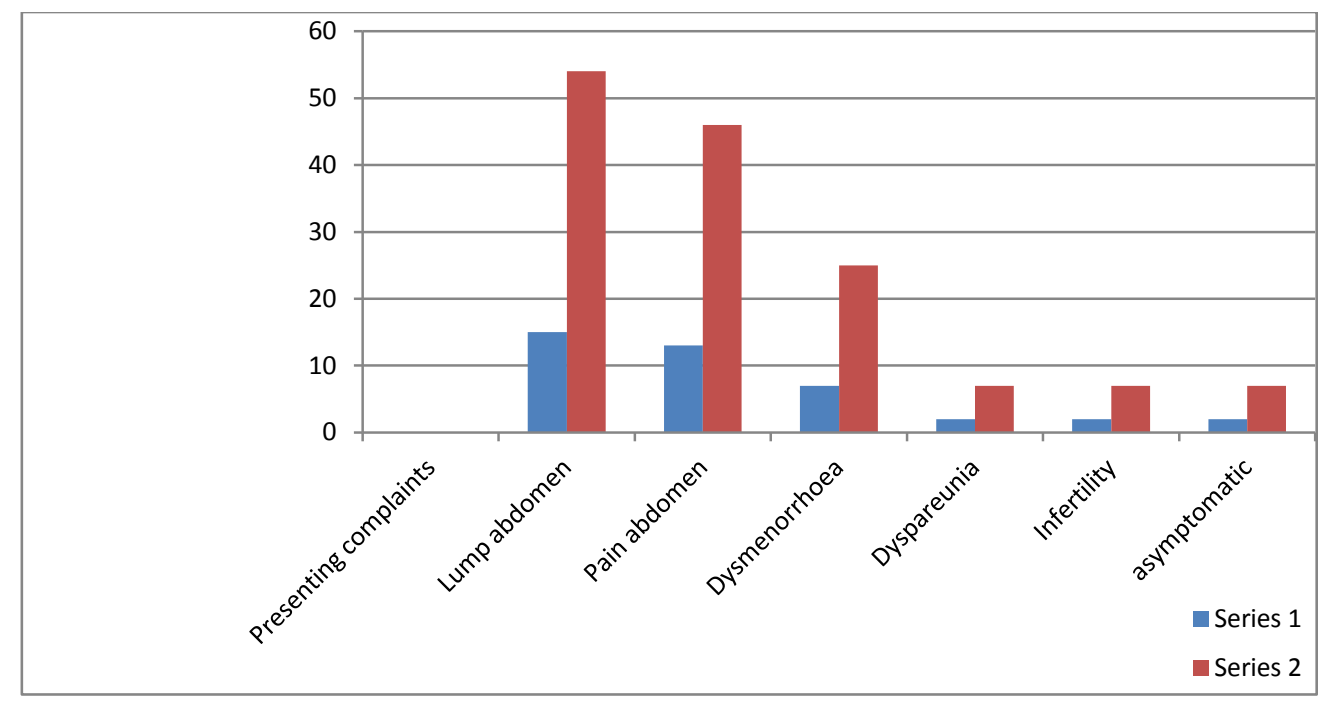

b) Presenting complaints of women with borderline/ malignant complaints

\begin{tabular}{|l|c|c|}
\hline & Number & $\%$ \\
\hline Lump abdomen & 11 & 55 \\
\hline Loss of weight/cachexia/weakness & 9 & 45 \\
\hline Pain abdomen & 7 & 35 \\
\hline distension & 7 & 35 \\
\hline asymptomatic & 2 & 10 \\
\hline
\end{tabular}

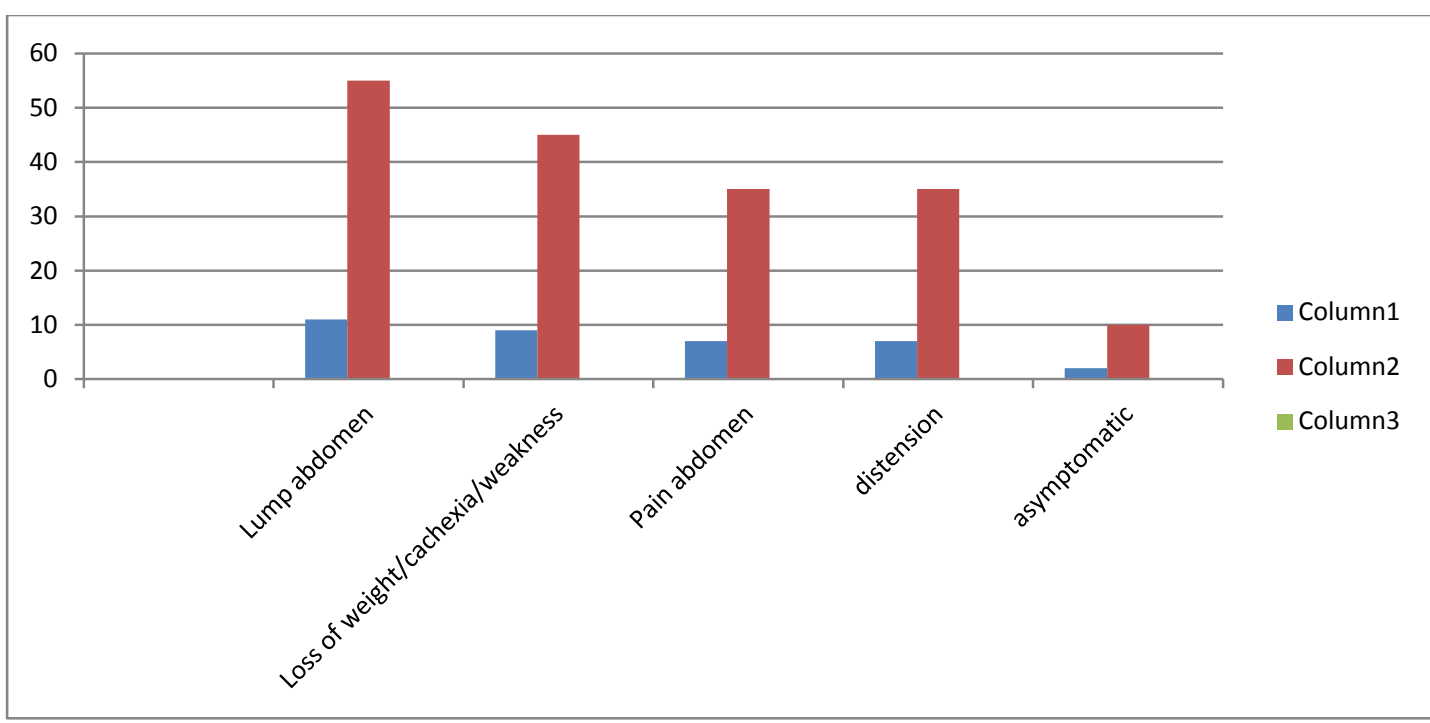




\section{JMSCR Vol||06||Issue ||04||Page 293-297||April}

c) 38 purely cystic lesions were studied. The presence of T2 shading was recorded. There were 7 patients with 4 having bilateral endometriotic cysts (>3 c.m.) and rest having smaller cysts. All of them were correctly identified on MRI. The mean age of presentation was $30 \mathrm{yrs}$ with an age range of $17-49$ years.
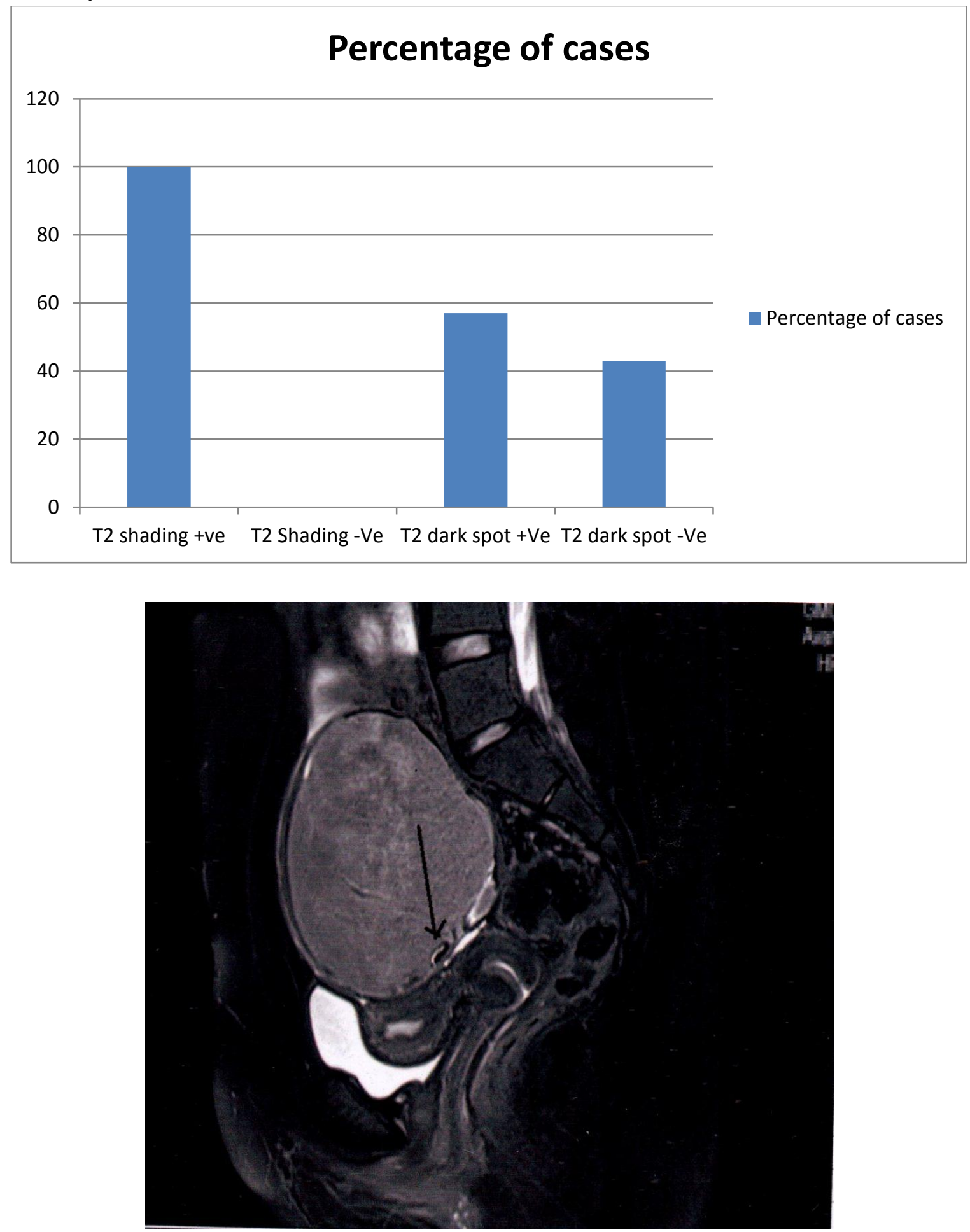

T2 WI showing shading within the cyst 


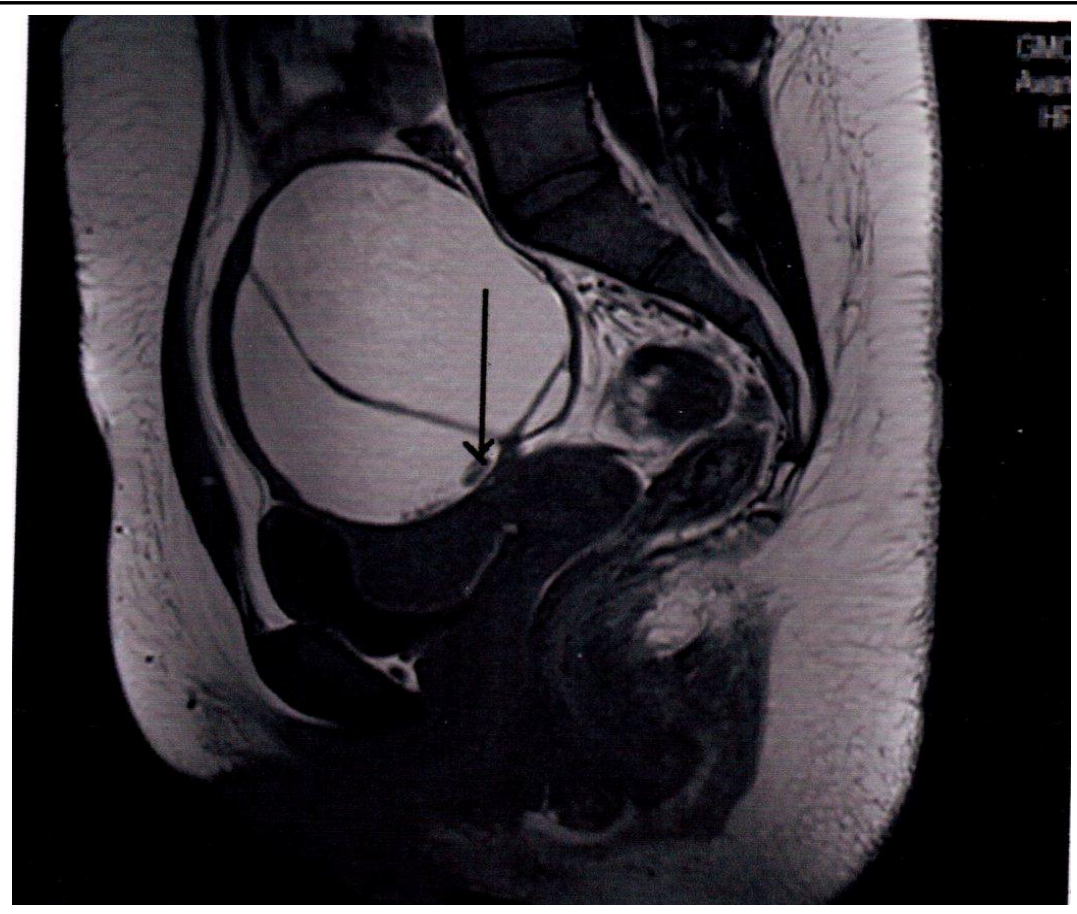

T1 WI showing a multi loculated hyperintense lesion.

Table showing association of T2 shading with Endometrioma

\begin{tabular}{|l|c|c|c|c|c|c|}
\hline & \multicolumn{2}{|c|}{ Endometrioma +Ve } & \multicolumn{2}{|c|}{ Endometrioma -Ve } & \multicolumn{2}{|c|}{ Total } \\
\hline Shading +Ve & 14 & $37 \%$ & 8 & $21 \%$ & 22 & $58 \%$ \\
\hline Shading -Ve & 0 & $0 \%$ & 16 & $42 \%$ & 15 & $42 \%$ \\
\hline
\end{tabular}

Table showing association of $\mathrm{T} 2$ dark spot sign with Endometrioma

\begin{tabular}{|l|c|c|c|c|c|c|}
\hline & \multicolumn{2}{|c|}{ Endometrioma +Ve } & \multicolumn{2}{|c|}{ Endometrioma -Ve } & \multicolumn{2}{|c|}{ Total } \\
\hline T2 dark spot +ve & 8 & $21 \%$ & 1 & $2.5 \%$ & 9 & $23.5 \%$ \\
\hline T2 dark spot -ve & 6 & $16 \%$ & 23 & $60.5 \%$ & 29 & $75.5 \%$ \\
\hline
\end{tabular}

Table showing sensitivity specificity of MR findings:

\begin{tabular}{|l|c|c|c|c|c|}
\hline MR finding & Sensitivity (\%) & Specificity (\%) & PPV (\%) & NPV (\%) & P value \\
\hline T2 dark spot & $57 \%$ & $95.8 \%$ & $88.9 \%$ & $79.3 \%$ & 0.0005 \\
\hline T2 shading & $100 \%$ & $66.7 \%$ & $63 \%$ & $100 \%$ & $<0.0001$ \\
\hline
\end{tabular}

Diagnostic accuracy (balanced) of MRI in diagnosing Endometriomas using T2 shading $83.35 \%$.

Diagnostic accuracy (balanced) of MRI in diagnosing Endometriomas using T2 dark spot shine $76.4 \%$.

\section{Interpretation and Conclusion}

Eight of the fourteen endometriomas (21\%), 0 of 7 haemorrhagic cysts and one of the other cystic lesions demonstrated T2 dark spot. All of the fourteen endometrimas $100 \%$ all of 7 haemorrhagic cysts and 2 others showed T2 shading.

MR imaging has been shown to be an accurate imaging modality in diagnosing endometriomas. In this study we sought to evaluate the value of $\mathrm{T} 2$ dark spot and T2 shading in USG proven completely cystic lesion. The sensitivity, specificity, PPV and NPV has been as mentioned above. The results were consistent with a study done by Corwin MT et al.

\begin{tabular}{|l|c|c|c|c|}
\hline & Sensitivity & Specificity & PPV & NPV \\
\hline Corwin MT et al & 93 & 45 & 72 & 81 \\
\hline Present study & 100 & 66.7 & 63 & 100 \\
\hline
\end{tabular}




\section{JMSCR Vol||06||Issue||04||Page 293-297||April}

\section{References}

1. Elizabeth A. Sadowski, Jessica B. Robbins, Andrea G. Rockall, Isabelle Thomassin-Naggara. (2018) A systematic approach to adnexal masses discovered on ultrasound: the ADNEx MR scoring system. Abdominal Radiology 43:3, 679695.

2. C. Bourgioti, O. Preza, E. Panourgias, K. Chatoupis, A. Antoniou, M.E. Nikolaidou, L.A. Moulopoulos. (2017) MR imaging of endometriosis: Spectrum of disease. Diagnostic and Interventional Imaging 98:11, 751-767.

3. Michael T. Corwin, MD Eugenio O. Gerscovich, MD Ramit

Lamba, MD Machelle Wilson, PhD John P. McGahan, MD, Differentiation of Ovarian Endometriomas from Hemorrhagic Cysts at MR Imaging: Utility of the T2 Dark Spot Sign, April 2014,126-32.

4. Out water EK, Mitchell DG(1996) normal overies and functional cyst MR appearance. Radiology 198: 397-402.

5. Pretorius ES, Out water EK Hunt JL, et al. Magenatic resonance imaging of the ovary. Top Magn Reson Imaging. 2001; 12: $131 Y 146$. 